Document downloaded from:

http://hdl.handle.net/10251/140826

This paper must be cited as:

Soriano Rodríguez, MD.; Garcia-Gonzalez, E.; Concepción Heydorn, P.; Rodella, C.; López Nieto, JM. (2017). The Self-Organized Transformation from Hexagonal to Orthorhombic Bronze of Cs-Nb-W-O Mixed Oxides Prepared Hydrothermally. Crystal Growth \& Design. 17(12):6320-6331. https://doi.org/10.1021/acs.cgd.7b00999

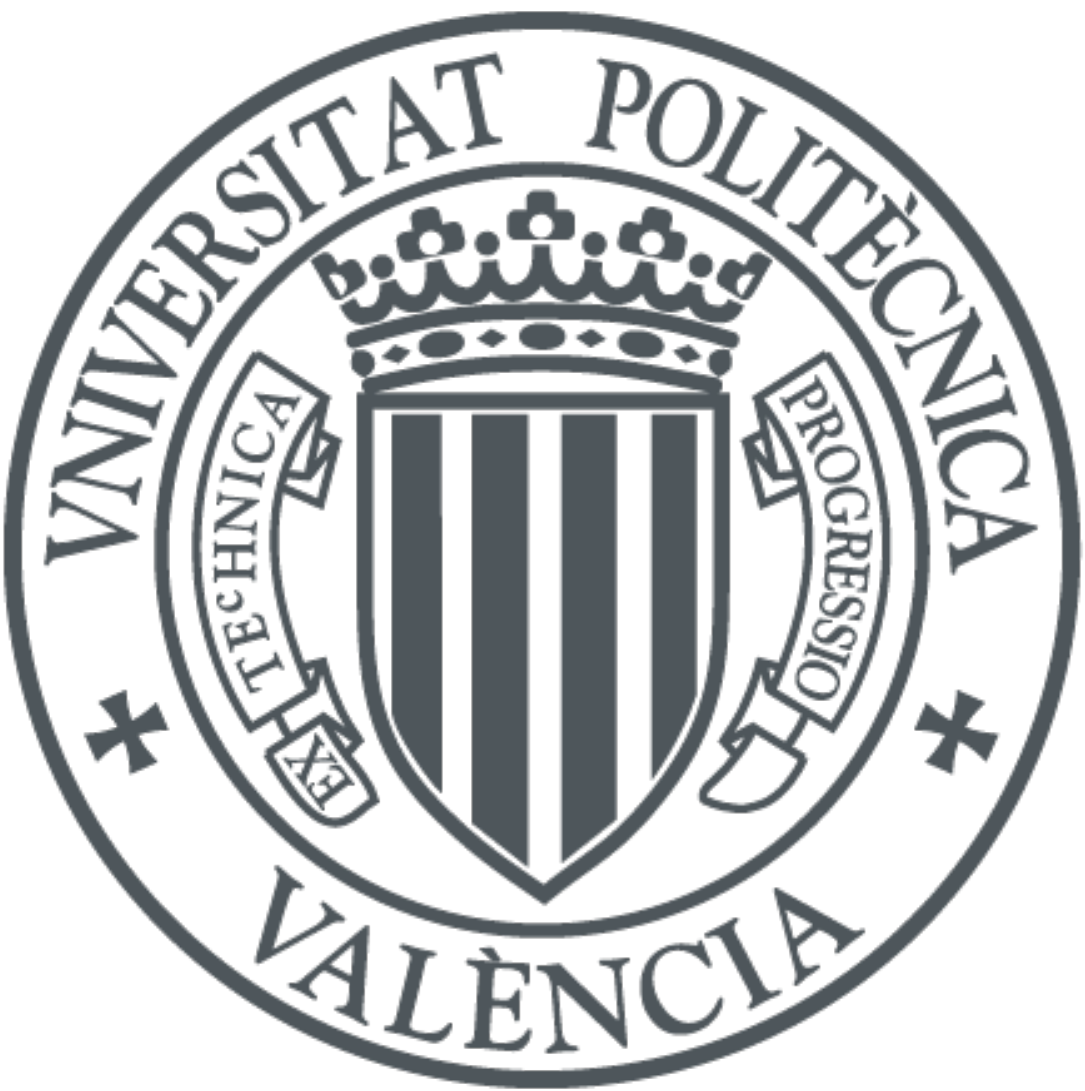

The final publication is available at

https://doi.org/10.1021/acs.cgd.7b00999

Copyright American Chemical Society

Additional Information 


\title{
The Self-Organized Transformation from Hexagonal to Orthorhombic Bronze of Cs-Nb-W-O Mixed Oxides Prepared Hydrothermally
}

\author{
Maria D. Soriano a , Ester García-González ${ }^{\text {b,* }}$, Patricia Concepción ${ }^{a}$, Cristiane B. \\ Rodella ${ }^{c}$, Jose M. López Nieto ${ }^{\text {a,* }}$
}

a) Instituto de Tecnología Química, Universitat Politècnica de València- Consejo Superior de Investigaciones Científicas, Avda. Los Naranjos s/n, 46022 Valencia (Spain)

b) Departamento Química Inorgánica, Facultad de Ciencias Químicas, Universidad Complutense, 28040 Madrid (Spain).

c) Brazilian Synchrotron Light Laboratory (LNLS)/Brazilian Center for Research in Energy and Materials (CNPEM), C. P. 6192, 13083-970, Campinas (Brazil).

* To whom correspondence should be addressed (FAX: +34966877809). Email address: jmlopez@itq.upv.es and esterg@quim.ucm.es 


\begin{abstract}
The thermal transformation of hydrothermally prepared Cs-Nb-W-O mixed oxides has been studied in the $25-1000^{\circ} \mathrm{C}$ temperature range. Structural evolution of the prepared solids was monitored by in-situ synchrotron X-ray diffraction (XRD), absorption spectroscopy (XAS) techniques and conventional powder X-ray diffraction and studied by thermogravimetric analysis, infrared (FTIR) and Raman spectroscopy and high resolution transmission electron microscopy (HRTEM and STEM). The as-grown solids show the hexagonal tungsten bronze (HTB) structure, which can be stabilized above $900{ }^{\circ} \mathrm{C}$ depending on the chemical composition. From this temperature, solids are selectively transformed into the orthorhombic Cs0.5( $\left.\mathrm{Nb}_{2.5} \mathrm{~W}_{2.5}\right) \mathrm{O}_{14}$ structure-type. The same results are obtained for $\mathrm{Cs}_{0.5}\left(\mathrm{Nb}_{2.5} \mathrm{~W}_{2.5-\mathrm{x}} \mathrm{M}_{\mathrm{x}}\right) \mathrm{O}_{3}$, with $\mathrm{M}=\mathrm{V}$ or $\mathrm{Mo}$; $(\mathrm{x}=0-1.25)$. A mechanism for the quantitative transformation at high temperature is proposed in terms of the relative occupancy of the hexagonal channels in the HTB-type phase as well as the $\mathrm{Nb} /(\mathrm{W}+\mathrm{V})$ ratio.
\end{abstract}

Keywords: Cs-Nb-W mixed oxides, Crystalline W-Nb-O, HTB-type structure, orthorhombic M1 phase, bronzes. 


\section{INTRODUCTION}

In the last two decades, there has been an increased interest in the synthesis and characterization of multicomponent mixed oxides bronzes since they are good candidates for a wide variety of applications (electronic devices, adsorbents, gas sensors devices or catalysts). ${ }^{1-8}$ This is so because they offer a diversity of chemical compositions, in which $\mathrm{MO}_{6}$ octahedra and/or $\mathrm{MO}_{7}$ pentagonal bipyramids (with $\mathrm{M}$ elements presenting different oxidation states) form structural frameworks with empty or partially occupied n-fold channels.

Mo-based bronzes have been extensively studied because of their interesting physical properties. In particular, their highly anisotropic transport properties, ${ }^{2-5,7}$ are of interest in applications such as electrochromic devices, batteries, solar cells, sensors or electrocatalysts. 1, 2, 7-10 More recently, they have been used as efficient catalysts as well, ${ }^{10-16}$ especially those corresponding to the so-called M1 phase, with orthorhombic symmetry and nanoscale 5-, 6- and 7-fold channels, ${ }^{11-16}$ which are very selective catalysts in the oxidation and ammoxidation of propane ${ }^{10-15}$ and in the oxidative dehydrogenation of ethane to ethylene. ${ }^{16}$ In the Mo-V-Te-Nb-O system, the M1 phase forms a multiple active catalyst together with the so-called M2 phase (a pseudohexagonal bronze), among which a synergistic effect has been proposed that is still the subject of controversy. ${ }^{11}$ M2 resembles the hexagonal tungsten bronze (HTB) structure with $\mathrm{MO}_{6}$ octahedra sharing corners and forming only hexagonal channels. Different HTB-type phases have been proposed as active and selective catalysts due to their capability to present acid and/or redox properties depending on their chemical composition. ${ }^{17-20}$ 
Similarly, $\mathrm{W}$ and $\mathrm{W}-\mathrm{Nb}$ oxide bronzes have been also investigated owing to their interesting structural, electronic and electrochromic properties. Thus, they can be used as efficient gas sensors, ${ }^{1,3,17}$ adsorbents or ion exchangers, ${ }^{18,19}$ and active and selective catalysts as well. ${ }^{20}$

Lundberg and Sundberg reported two complex structures in the cesium-niobiumtungsten-oxide system: ${ }^{21}$ the orthorhombic $\mathrm{Cs}_{0.5}(\mathrm{Nb}, \mathrm{W}) 5 \mathrm{O}_{14}$ structure (which resembles strongly M1 phase in Mo-containing bronzes) and $\mathrm{Cs} 3(\mathrm{Nb}, \mathrm{W})_{27} \mathrm{O}_{73}$ with tetragonal symmetry. More recently, the crystal phase $\mathrm{Cs}_{0.44} \mathrm{Nb}_{2.54} \mathrm{~W}_{2.46} \mathrm{O}_{14}$, isostructural with $\mathrm{Cs}_{0.5}(\mathrm{Nb}, \mathrm{W})_{5} \mathrm{O}_{14}$, has been also reported. ${ }^{22}$

The so-called M1 phase of Mo-V-Te-Nb-O ${ }^{11-15}$ is often considered isostructural with the orthorhombic $\mathrm{Cs}_{0.5}(\mathrm{Nb}, \mathrm{W})_{5} \mathrm{O}_{14}$ proposed by Lundberg and Sundberg ${ }^{21}$ in spite of the empty heptagonal channels which are partially occupied in the Cs-containing phase. It is the presence of these empty heptagonal channels what seems to be related to its high selectivity in the activation of short chain alkanes. ${ }^{11-16}$ The hexagonal channels can contain $\mathrm{Te}^{4+}$ ions in the former compound and in the latter compound they are partially occupied by $\mathrm{Cs}^{+}$ions ${ }^{21,22}$ causing the disappearance of the catalytic activity. Stability and crystallinity of M1 is strongly related to niobium content, although the formation mechanism of this crystal phase is still under discussion. $\mathrm{Cs}^{+}$ions must play a decisive role in the stability of $\mathrm{Cs}_{0.5}(\mathrm{Nb}, \mathrm{W})_{5} \mathrm{O}_{14}$ which has low flexibility in composition and needs a precise $\mathrm{Nb} / \mathrm{W}$ ratio to be formed. ${ }^{21-25}$ Thus, depending on the Cs and $\mathrm{Nb}$ content, the formation of $\mathrm{Nb}_{2} \mathrm{~W}_{3} \mathrm{O}_{14}, \mathrm{Cs}_{0.25}\left[\mathrm{Nb}_{2.25} \mathrm{~W}_{2.75} \mathrm{O}_{14}\right]$ (isostructural with the oxidic bronze $\mathrm{Mos}_{5} \mathrm{O}_{14}$ ), or the orthorhombic $\mathrm{Cs}_{0.5}\left[\mathrm{Nb}_{2.5} \mathrm{~W}_{2.5} \mathrm{O}_{14}\right]$ can be observed. In addition, low Nb concentration promotes the formation of the HTB crystal phase. ${ }^{24,}{ }^{25}$ HTB-type phases containing big alkali ions such as $\mathrm{Cs}^{+}$or $\mathrm{K}^{+}$in the hexagonal tunnels lose the catalytic activity observed in the M2-phase but increase the 
thermal stability of the crystal phase and give rise to interesting optical properties as in the case of the mixed valence compounds $\mathrm{K}_{\mathrm{xWO}}{ }^{26}$ or $\mathrm{Cs}_{0.32} \mathrm{WO}_{3}$ that behaves as promising photocatalyst. ${ }^{27} \mathrm{Nb}$ - or V-doped hexagonal tungsten bronze can be obtained by a partial substitution of tungsten by vanadium or niobium, ${ }^{28,29}$ although other crystalline structures can be observed depending on the $\mathrm{V}$ or Nb contents. ${ }^{20,28-30}$

Various preparation methods have been reported to obtain Mo-containing M1type -materials and it has been always challenging to prepare it as a single phase. ${ }^{11-16,31-}$ ${ }^{34}$ These procedures include precipitation-evaporation, hydrothermal or reflux and the as prepared amorphous materials must be heat-treated at ca. $600^{\circ} \mathrm{C}$ under inert atmosphere to obtain the desired M1 crystal phase.

In the case of Cs-W-O materials, hydrothermal methods have been also reported for obtaining HTB-type phases ${ }^{35,36}$ or the orthorhombic phase, ${ }^{37}$ although these crystal phases has been usually prepared by different procedures such as solid-state reaction, slurry route or "flash" method. ${ }^{21,33,34}$

In this paper we show the use of hydrothermal synthesis for the preparation of the HTB-type Cs-Nb-W-O bronze and how the thermal treatment above $950^{\circ} \mathrm{C}$ causes the complete transformation of the hexagonal structure into the orthorhombic $\mathrm{Cs}_{0.5}(\mathrm{Nb}, \mathrm{W})_{5} \mathrm{O}_{14}$ crystal phase. Our understanding on this transformation process can contribute to a comprehensive scenario for the crystal growth of the M1 phase and its relationship with the M2 phase, with which it is functionally linked.

\section{EXPERIMENTAL}

\subsection{Synthesis of materials}


The samples have been prepared by hydrothermal synthesis from gels containing ammonium metatungstate hydrate (99.99\%, Aldrich), caesium nitrate (99\%, Aldrich), niobium oxalate monohydrate (99\%, ABCR) and, when appropriate, vanadyl sulphate (>97\%, Sigma-Aldrich) and ammonium heptamolybdate (>97\%, Sigma-Aldrich). Mixtures contained a $\mathrm{Cs} / \mathrm{Nb} / \mathrm{W}$ atomic ratio of $0.5 / 2.5 / 2.5$ and a metal/ $\mathrm{H}_{2} \mathrm{O}$ molar ratio of 0.004 (sample A) or 0.01 (sample B) and; in both cases, the final $\mathrm{pH}$ was fixed to 2.5.

The gels were loaded in Teflon-lined stainless-steel autoclaves, heated at $175{ }^{\circ} \mathrm{C}$ for $48 \mathrm{~h}$ and subsequently cooled to room temperature. The precipitates were filtered off, washed and dried in air at $100^{\circ} \mathrm{C}$ for $16 \mathrm{~h}$ to obtain the pristine samples. For comparison, two V-containing samples were prepared by partial substitution of $\mathrm{Nb}$ or $\mathrm{W}$, with $\mathrm{Cs} / \mathrm{Nb} / \mathrm{W} / \mathrm{V}$ ratio in the synthesis gel of $0.5 / 1.5 / 2.5 / 1$ and $0.5 / 2.5 / 1.5 / 1$ and a metal/ $\mathrm{H}_{2} \mathrm{O}$ molar ratio of 0.01 (samples $\mathbf{C}$ and $\mathbf{D}$, respectively). In addition, a Mocontaining sample was also prepared by partial substitution of $\mathrm{W}$ by Mo with $\mathrm{Cs} / \mathrm{Nb} / \mathrm{W} / \mathrm{Mo}$ atomic ratio in the synthesis gel of 0.5/2.5/1.25/1.25 (sample $\mathbf{E}$ ). Samples B1 and C1 were prepared from synthesis gels with excess of Cesium, i.e. with $\mathrm{Cs} / \mathrm{Nb} / \mathrm{W} / \mathrm{V}$ molar ratios of 1.5/1.5/2.5/0 and 1.5/2.5/1.5/1, respectively.

The as-synthesized dried solids named as $\mathbf{X}-\operatorname{pr}(\mathbf{X}=\mathbf{A}, \mathbf{B}, \mathbf{B} 1, \mathbf{C}, \mathbf{C} 1, \mathbf{D}$ and $\mathbf{E})$ were calcined in the $400-1000{ }^{\circ} \mathrm{C}$ temperature range $(4 \mathrm{~h}$ in an air-stream at a heating rate of $\left.10^{\circ} \mathrm{C} / \mathrm{min}\right)$. The corresponding calcined samples were named as $\mathbf{X}$-t, where $\mathbf{t}$ refers to the heating temperature. The main characteristics of samples are shown in Table 1.

\section{Table 1}

\subsection{Characterization of materials}


Room temperature powder X-ray diffraction (XRD) patterns were collected using an Enraf Nonius FR590 sealed tube diffractometer, with a monochromatic $\mathrm{CuK} \alpha 1$ source operating at $40 \mathrm{kV}$ and $30 \mathrm{~mA}$.

Dynamic heating experiments were carried out in situ using synchrotron radiation on XPD beamline at the Brazilian Synchrotron Light Laboratory (LNLS) with the wavelength of $1.548943 \AA$ ( $8 \mathrm{keV})$. Data collection was conducted using the in house designed furnace installed at the Huber diffractometer of the beamline in reflection mode (Bragg-Brentano geometry). XRD patterns were obtained by a onedimensional Mythen-1K detector (Dectris) installed $\approx 1 \mathrm{~m}$ away from the furnace. The furnace was initially calibrated by using $\mathrm{MgO}$ as standard to determine the actual temperature at the sample position during data collection. A data set was collected every $2.5 \mathrm{~min}$ from room temperature to $975{ }^{\circ} \mathrm{C}$ with a $2 \Theta$ interval from 3.0 to $32.0^{\circ}$. A heating rate of $7{ }^{\circ} \mathrm{C} \min ^{-1}$ was used under an atmosphere of either synthetic air or helium at a flow rate of $100 \mathrm{~mL} \min ^{-1}$. Once $975^{\circ} \mathrm{C}$ was reached the furnace was held isothermally while data was collected. At the end of the isothermal treatment, a long scan was performed from $2 \theta=3$ to $110^{\circ}$. Finally, the furnace was cooled down to room temperature and a new long scan was collected.

Termogravimetric analysis (TG) was performed on a Mettler Toledo TGA/SDTA851 instrument in the temperature range $20-600{ }^{\circ} \mathrm{C}$ with a 0.02 g sample. The heating rate was $10^{\circ} \mathrm{C} \mathrm{min}^{-1}$ and the flow air $100 \mathrm{ml} \mathrm{min}$.

Infrared spectra were recorded at room temperature in the $300-4000 \mathrm{~cm}^{-1}$ region with a Nicolet 205xB spectrophotometer equipped with a Data station at a spectral resolution of $1 \mathrm{~cm}^{-1}$ and accumulations of 128 scans. Samples were pressed into wafers after the mixture and ground with $\mathrm{KBr}$. 
Raman spectra were performed with an "in via" Renishaw spectrometer, equipped with an Olympus microscope. The exciting wavelength was $514 \mathrm{~nm}$ from a Renishaw HPNIR laser with a power of approximately $15 \mathrm{~mW}$ on the sample. Previous dehydration of catalysts (under $20 \mathrm{ml} \mathrm{min}^{-1}$ argon flow at $150-250^{\circ} \mathrm{C}$ ) was carried out using a home-designed microreactor for in situ Raman spectroscopy measurement.

X-ray absorption near edge spectroscopy (XANES) at the Nb K-edge (18986 eV) and W L3-edge (10207 eV) was performed at the XAFS1 beamline at the Brazilian Synchrotron Light Laboratory (LNLS). The measurements were performed using a Si(111) crystal monochomator, with an energy resolution of $1.7 \times 10^{-4} \mathrm{E} / \mathrm{dE}$, and $\mathrm{Rh}$ mirrors were used to focus the beam. Three ionization chambers were filled with optimal $\mathrm{He} / \mathrm{Ar}$ gas mixture at a total pressure of 1.5 bars in order to have absorption of $10 \%$ in I0 and $70 \%$ in I1 and I2 at the Nb K-edge and W L3-edge. The spectra were collected in transmission mode. The monochromator was calibrated with an Au foil, which was constantly monitored during collection of the spectra in order to account for small energy shifts $(<1 \mathrm{eV})$ during the measurements. The pre-edge region was scanned with steps of $5 \mathrm{eV}$. Along the edge, the step size was reduced to $0.3 \mathrm{eV}$ in order to obtain the adequate resolution for the X-ray absorption near edge structure (XANES). Athena/Artemis software packages were used to extract the EXAFS signal from the measured absorption spectra using standard procedures. XANES spectra of the reference materials $\mathrm{Nb}_{2} \mathrm{O}_{5}$ and $\mathrm{WC}$ were recorded at room temperature.

Samples for transmission electron microscopy (TEM) were ultrasonically dispersed in $n$-butanol and transferred to carbon coated copper grids. Selected area electron diffraction (SAED) and high resolution transmission electron microscopy (HRTEM) were performed on a JEOL JEM300F electron microscope by working at 300 $\mathrm{kV}$ (point resolution of $0.17 \mathrm{~nm}$ ). Crystal-by-crystal chemical microanalysis was 
performed in the same microscope by energy-dispersive X-ray spectroscopy (XEDS) with an ISIS 300 X-ray microanalysis system (Oxford Instruments) with a detector model LINK “Pentafet” (resolution 135 eV). High angle annular dark field (HAADF) scanning TEM (STEM) work was performed on an ARM200cF microscope, fitted with a condenser lens aberration corrector (point resolution in STEM mode of $0.08 \mathrm{~nm}$ ). HAADF images were acquired with an inner acceptance angle of 90 mrad.

\section{RESULTS AND DISCUSSION}

\subsection{X-Ray Powder Diffraction}

Figure 1 shows the X-ray Powder Diffraction patterns of the as synthesized samples (Figure 1a) and after the heat-treatment at 600 and $1000{ }^{\circ} \mathrm{C}$ (Figures $1 \mathrm{~b}$ and $1 \mathrm{c}$, respectively). In spite of the broadness of the diffraction maxima, patterns of the B-pr and C-pr materials can be easily indexed on the basis of the hexagonal cesium tungsten bronze $\mathrm{Cs}_{0.2} \mathrm{~W}_{0.8} \mathrm{Nb}_{0.2} \mathrm{O}_{3}$ (ICDD 00-39-0812) ${ }^{23}$ (Figure 1a). Patterns of the A-pr, D-pr and E-pr samples resemble those of the other two samples but the poor crystallinity does not allow a precise assignment, and the corresponding diffraction pattern could be compatible with different bronzoid-type phases.

\section{Figure 1}

Thermal treatment up to $600^{\circ} \mathrm{C}$ produces structural changes in the samples and diffraction patterns can be assigned in different ways, depending on the composition of the gel in the synthesis step (Figure 1b, Table 1). Crystallinity of A-600, B-600, D-600 and E-600 samples do not improve, but patterns of the four samples become more similar by displaying sharp diffraction peaks at $\sim 22^{\circ}$ and $\sim 46^{\circ}\left({ }^{\circ} 2 \theta\right)$. Sample C-600 
shows good crystallinity and the whole pattern can be unambiguously assigned to the $\mathrm{Cs}_{0.2} \mathrm{~W}_{0.8} \mathrm{Nb}_{0.2} \mathrm{O}_{3}$ HTB-type structure. At this point it is important to mention that diffraction patterns of samples, A-600, D-600 and E-600 are imprecise so they are compatible with those obtained for M1 in Mo-V based materials in the early stages of crystallization. ${ }^{12-16}$

After treatment at $1000^{\circ} \mathrm{C}$, sample $\mathbf{C}$ does not change significantly and $\mathbf{C}-\mathbf{1 0 0 0}$ is fully indexed on the basis of the unit cell of $\mathrm{Cs}_{0.2} \mathrm{~W}_{0.8} \mathrm{Nb}_{0.2} \mathrm{O}_{3} \mathrm{HTB}$-type structure (Figure 1c). Diffraction pattern of A-1000 can also be indexed on the basis of the HTBtype structure. However, samples B, D and E undergo an important structural transformation and diffraction patterns of B-1000, D-1000 and E-1000 can be assigned to the orthorhombic Cs0.52[W2.46 $\left.\mathrm{Nb}_{2.5} \mathrm{O}_{14}\right]$ (ICDD 01-076-5882), ${ }^{22}$ isostructural with the so-called M1 phase in the Mo-V-X-Y (X= Te, Sb; Y= Nb or Ta) systems. ${ }^{11-16}$

At this point it is important to emphasize that all diffraction patterns shown in figure 1 share in common the two diffraction maxima at $\sim 22^{\circ}$ and $\sim 46^{\circ}\left({ }^{\circ} 2 \theta\right)$ which are always sharp and intense although the material has low crystallinity. These maxima correspond to (00l) reflections and are common to every crystal phase constituted by MO6 octahedra sharing corners. In this sense, (00l) reflections have been labeled in reference patterns of Figure 1 to show their correspondence in both structures.

The in situ dynamic heating experiment performed in air on sample B-pr by using X-ray synchrotron radiation, confirms the high thermal stability of the HTB-type structure (Figure 2a). From room temperature to $945^{\circ} \mathrm{C}$, patterns correspond to the CsHTB type structure, although diffraction maxima at $\approx 22^{\circ}$ and $\approx 28^{\circ}\left({ }^{\circ} 2 \theta\right)$ increase their intensity and become narrower with temperature. Maximum at $22.71^{\circ}$ shifts to $22.56^{\circ}$ at $600^{\circ} \mathrm{C}$. A similar displacement has been reported in $\mathrm{Nb}$-doped hexagonal $\mathrm{WO}_{3}$ samples, 
related to the expansion of d001 spacing when increasing the $\mathrm{Nb} / \mathrm{W}$ ratio ${ }^{38}$ and in the HTB-type systems Cs0.25Nby $\mathrm{W}_{1-\mathrm{y}} \mathrm{O}_{3}$ and $\mathrm{Cs}_{0.3} \mathrm{Nb}_{\mathrm{y}} \mathrm{W}_{1-\mathrm{y}} \mathrm{O}_{3}(0.0 \leq \mathrm{y} \leq 0.25$ and $0.0 \leq \mathrm{y} \leq$ 0.3 , respectively). ${ }^{24} \mathrm{New}$ diffraction maxima appear at $960^{\circ} \mathrm{C}$, their intensity increasing at $975^{\circ} \mathrm{C}$. At this temperature, the furnace was held isothermally and in situ diffraction patterns were then acquired at different times. Comparison between consecutive patterns (Figure 2b) shows the progressive formation of the orthorhombic $\mathrm{Cs}_{0.5}(\mathrm{Nb}, \mathrm{W})_{5} \mathrm{O}_{14}$ crystal phase. The conventional powder X-ray diffraction patterns of the B-series, calcined at different temperatures from 600 to $1000{ }^{\circ} \mathrm{C}$, are shown in Figure S1 (supporting information). The evaluation of the patterns through the series confirms the previous results and the HTB type structure is observed up to $800{ }^{\circ} \mathrm{C}$ (patterns b-d). Above $900{ }^{\circ} \mathrm{C}$ (patterns e and f), diffraction maxima can be fully assigned to the $\mathrm{Cs}_{0.5}(\mathrm{Nb}, \mathrm{W})_{5} \mathrm{O}_{14}$ phase. All the above suggest that the transformation takes place at high temperature although it is not kinetically favored and needs a certain time for crystallization.

\section{Figure 2}

Samples prepared from synthesis gels with high $\mathrm{Cs} / \mathrm{Nb}$ ratio (Table 1, B1- and C1-series), exhibit diffraction patterns that can be assigned on the basis of the Cs-HTB type structure in the whole temperature range (Figure S2, supporting information).

At this point it is important to mention that the $\mathrm{Cs} 0.5(\mathrm{Nb}, \mathrm{W})_{5} \mathrm{O}_{14}$ crystal phase was obtained by Hibst et al. ${ }^{15,34}$ from an aqueous suspension containing niobium oxalate, ammonium paratungstate and $\mathrm{CsCO}_{3}$, spray-dried and further calcined in air. As an important difference, no phase transformation is observed and the orthorhombic phase is obtained after calcination at $1000{ }^{\circ} \mathrm{C}$ from the as-prepared solid, which is semicrystalline up to at $700^{\circ} \mathrm{C}$. 


\subsection{Electron Microscopy}

Materials were further investigated by electron diffraction and high-resolution electron microscopy. The samples calcined at $600^{\circ} \mathrm{C}$ (i.e. samples A-, B-, D- and E600) are constituted by agglomerates of nanocrystallites $10-50 \mathrm{~nm}$ size and exhibit a typical electron diffraction ring pattern (Figure 3a). The set of rings indicates the nanocrystalline nature of the sample and allows a complete indexation to the Cs-HTB type structure, in agreement with X-ray diffraction data. Figure 3b corresponds to a low magnification electron micrograph of a group of crystals of the B-600 sample and illustrates very well the above facts. The analysis of the crystals by EDXS shows chemical compositions corresponding to the hexagonal bronzoid phases $\mathrm{Cs}_{\mathrm{x}} \mathrm{Nb}_{\mathrm{y}} \mathrm{W}_{1-\mathrm{y}} \mathrm{O}_{3}$ for the crystallites constituting the agglomerates (see Table 1), although the low Cs content has to be mentioned. Figure 3c shows one of these small crystals in the [100] projection and the corresponding Fourier transform (FFT) corroborates its crystal structure. Agglomerates of nanoparticles are also found where tungsten is the minor component and that could correspond to different pseudo bronze type phases. Their poor crystallinity allows only the identification of a d spacing of $\sim 4 \AA\left(2 \theta \approx 22^{\circ}\right)$, thus contributing to the maxima observed in the diffraction pattern (please note that, as previously stated, reflections (00l) on Figure 3a are common to every crystal phase constituted by $\mathrm{MO}_{6}$ sharing corners octahedra). These results are in contrast with the observations on sample C-600, constituted by well-defined crystallites of the Cs-HTB phase about $1 \mu \mathrm{m}$ in size.

\section{Figure 3}

Samples heat-treated at $1000{ }^{\circ} \mathrm{C}$ undergo a huge transformation and appear constituted by rod like crystals about $1 \mu \mathrm{m}$ in length and rod long-axis is parallel to $c$ - 
axis. Images shown on figure 4 correspond to two different projected crystals of the sample B-1000 oriented in the [102] (a) and [100] (b) zone axes of the $\mathrm{Cs}_{\mathrm{x}}(\mathrm{Nb}, \mathrm{W})_{5} \mathrm{O}_{14}$ crystal phase and the corresponding FFT are shown as insets. Crystal projections containing the c-axis or close orientations, are frequently obtained in the electron microscope, provided that [001] is the preferential growth direction and only a small amount of crystals grow in the $a b$ plane. Chemical composition of the samples became homogeneous as determined by EDXS and the individual analysis of the crystals show an important increase in niobium content. Composition is very close to that of the Cs 0.5 $\mathrm{Nb}_{2.5} \mathrm{~W}_{2.5} \mathrm{O}_{14}$ type-phase with variations from crystal to crystal in a very narrow range (see Table 1).

\section{Figure 4}

\subsection{Thermogravimetric analysis}

The thermal behavior of pristine samples was investigated by thermogravimetry under air atmosphere at a heating rate of $10^{\circ} \mathrm{C} / \mathrm{min}$ in the $25-800^{\circ} \mathrm{C}$ temperature range. All samples behave in a very similar way. Figure 5 shows the thermogravimetric results of samples B-pr and B-600. According to similar studies reported for the hexagonal bronze $\left(\mathrm{NH}_{4}\right)_{\mathrm{x}} \mathrm{WO}_{3}{ }^{39}$, three stages can be proposed in the case of $\mathbf{B}$-pr sample: i) a weight loss of ca. $3.15 \%$, up to about $220^{\circ} \mathrm{C}$, related to the desorption of water; ii) a weight loss of ca. $4.9 \%$, in the temperature range of $230-300^{\circ} \mathrm{C}$, assigned to the elimination of $\mathrm{NH}_{3}$ and structural water; and iii) a very low weight loss (ca. $0.2 \%$ ), from 300 to $450{ }^{\circ} \mathrm{C}$, related to elimination of structural $\mathrm{NH}_{3}$ and/or organic compounds. This suggests that a certain incorporation of $\mathrm{NH}_{4}{ }^{+}$ions occurs in the structure during the hydrothermal synthesis. Similar behavior is observed for the other samples. 


\section{Figure 5}

In the case of the sample calcined at $600^{\circ} \mathrm{C}$, only two steps are visible assigned to the elimination of water (ca. $0.68 \%$ below $200{ }^{\circ} \mathrm{C}$ ) and ammonia (ca. $0.32 \%$ above $300{ }^{\circ} \mathrm{C}$ ), and a total weight loss significantly lower than that observed for the pristine sample.

\subsection{Infrared and Raman spectroscopy}

The results of the thermogravimetric analysis are supported by infrared spectra of pristine and heat-treated samples in the regions characteristic of $\mathrm{O}-\mathrm{H}$ stretching (4000-3000 $\mathrm{cm}^{-1}$ ) and $\mathrm{H}_{2} \mathrm{O} / \mathrm{NH}_{3}$ bending $\left(1700-1400 \mathrm{~cm}^{-1}\right)$. The spectrum of assynthesized B-pr sample shows two intense broad bands at 3445 and $3145 \mathrm{~cm}^{-1}$ in addition to bands at 1628 and $1402 \mathrm{~cm}^{-1}$ (figure 6, spectrum a). Bands at 3445 and 1628 $\mathrm{cm}^{-1}$ are due to stretching and bending modes of $\mathrm{OH}$ groups and water molecules, ${ }^{38,40}$ whereas bands at 3145 (and a shoulder at $3014 \mathrm{~cm}^{-1}$ ) and $1402 \mathrm{~cm}^{-1}$ can be related to the stretching and bending modes of $\mathrm{NH}_{4}{ }^{+} \cdot{ }^{40}$

\section{Figure 6}

Some important changes are observed in the sample heat-treated at $600^{\circ} \mathrm{C}$ (Figure 6, spectrum b). The fact that the band at $3445 \mathrm{~cm}^{-1}$ is observed also in the sample heat-treated at $600^{\circ} \mathrm{C}$ suggests that this band could be related to the presence of a small amount of water in the structural channels. ${ }^{38}$ The absence of residual $\mathrm{NH}_{4}{ }^{+}$ions in this sample confirms the higher stability of the hexagonal $\mathrm{W}-\mathrm{Nb}-\mathrm{O}$ bronze in the presence of $\mathrm{Cs}^{+}$.

In the region $1100-400 \mathrm{~cm}^{-1}$, bands at $803,759,628,540$ and $434 \mathrm{~cm}^{-1}$ are observed for B-pr sample (Fig. 6, spectrum a). Bands at 817 and $690 \mathrm{~cm}^{-1}$ have been 
related to $v(\mathrm{~W}-\mathrm{O})$ and $v(\mathrm{O}-\mathrm{W}-\mathrm{O})$ vibrations in hexagonal $\mathrm{WO}_{3}$, respectively, ${ }^{41}$ whereas bands at 799, 746 and $625 \mathrm{~cm}^{-1}$, have been observed for $\mathrm{KNbW}_{2} \mathrm{O}_{9}$ hexagonal bronze. ${ }^{42}$ Accordingly, the bands 803, 759 and $628 \mathrm{~cm}^{-1}$ can be related to the stretching modes of $v(\mathrm{~W}-\mathrm{O}-\mathrm{M})(\mathrm{M}=\mathrm{W}$ or $\mathrm{Nb})$ in $\mathrm{WO}_{6}\left(\mathrm{NbO}_{6}\right)$ octahedra. However, bands at 540 and 434 $\mathrm{cm}^{-1}$ could be related to stretching vibrations $\delta(\mathrm{W}-\mathrm{O}-\mathrm{Me})(\mathrm{Me}=\mathrm{W}$ or $\mathrm{Nb})$ in $\mathrm{WO}_{6}$ (NbO6) octahedra.

At $600^{\circ} \mathrm{C}$, (Fig. 6, spectrum b) the band at $803 \mathrm{~cm}^{-1}$ shifts to higher frequencies, i.e. $830 \mathrm{~cm}^{-1}$, whereas the band at $750 \mathrm{~cm}^{-1}$ can be attributed to $\mathrm{W}-\mathrm{O}-\mathrm{Nb}$ stretching for $\mathrm{WO}_{6}\left(\mathrm{NbO}_{6}\right)$ octahedra in hexagonal bronze. ${ }^{42}$ The low frequency bands at 635, 554 and $434 \mathrm{~cm}^{-1}$ are related to $\mathrm{W}-\mathrm{O}-\mathrm{M}$ bridge vibrations. The intensity of all these bands rises for the sample heat-treated at $1000^{\circ} \mathrm{C}$ (Figure 6, spectrum c), in agreement with the increase in the crystallinity for this sample.

The partial substitution of $\mathrm{W}$ by $\mathrm{V}$ or Mo (sample $\mathbf{D}$ and $\mathbf{E}$ ) involves a decrease in the relative intensity of the band at $830 \mathrm{~cm}^{-1}$, thus unambiguously assigning this band to stretching of WO6 octahedra (see Figure S3).

Figure 6 (spectra d-f) shows the Raman spectra of samples of $\mathbf{B}$-series. Bands at 992 and $910 \mathrm{~cm}^{-1}$ are observed assigned to $\mathrm{W}=\mathrm{O}$ and $\mathrm{Nb}=\mathrm{O}$ terminal stretching modes. In addition, bands at 745 and 790, 755 and 820 for the sample B-1000 (Figure 6, spectrum $\mathrm{f}$ ), correspond to $\mathrm{W}-\mathrm{O}-\mathrm{M}$ bridges, where $\mathrm{M}=\mathrm{W}$ or $\mathrm{Nb}$, and the band at 319 $\mathrm{cm}^{-1}$ is assigned to vibration $\mathrm{Nb}-\mathrm{O}-\mathrm{Nb} .^{43,44}$

\subsection{XANES analysis at the Nb K-edge and W L3-edge}

XANES analysis at the Nb K-edge $(18.986 \mathrm{eV})$ was undertaken to investigate the local symmetry at the metal sites of the samples. The intensity of the features at the 
pre-edge region can be related to the symmetry of the metal atoms since the pre-edge step results from the $s \rightarrow d$ transitions. ${ }^{45}$ For a tetrahedral symmetry, this peak becomes more intense and clear when compared to a square pyramidal or octahedral geometry, which presents itself as a small shoulder in the spectrum. Figure 7a shows the normalized K-edge spectra of $\mathbf{B}$-pr and $\mathbf{B - 1 0 0 0}$ samples as well as that of the reference compound $\mathrm{Nb}_{2} \mathrm{O}_{5}$. From the intensity observed, it is likely that $\mathrm{Nb}$ atoms find themselves in a distorted octahedral geometry within the structure at room temperature, the geometry showing small changes as temperature increases. Figure $7 \mathrm{~b}$ presents the normalized Nb K-edge spectra of B-pr sample during the in-situ heat-treatment in the $50-1000^{\circ} \mathrm{C}$ temperature range. After the in situ data collection, only a very small change in the pre-edge is seen. The small decrease in the edge intensity may be due to a distortion within the structure as some of the $\mathrm{Nb}$ atoms may find themselves in a more distorted octahedral environment after exposure to high temperatures. This is the most likely case as the Nb atoms are expected to be present within distorted polyhedra. The derivate maximum of the sample and the reference compound $\mathrm{Nb}_{2} \mathrm{O}_{5}$ appear at the same position, indicating that $\mathrm{Nb}$ atoms are in +5 oxidation state. ${ }^{46}$

\section{Figure 7}

Figure 8 shows the normalized W L3-edge XANES spectra of B-pr during the in situ heat-treatment from 50 to $1000^{\circ} \mathrm{C}$. The steep white line at $10212 \mathrm{eV}$ could be attributed to the electronic transition from the $2 \mathrm{p} 3 / 2$ to the vacant $5 d$ orbitals and it is related to octahedral tungsten species. ${ }^{46,} 47 \mathrm{~A}$ small shift in the steep white line is observed after the isothermal treatment at $1000^{\circ} \mathrm{C}$. However, since the difference on the edge position is lower than $1.5 \mathrm{eV}$, it is difficult to use these results quantitatively. ${ }^{46}$

\section{Figure 8}


In addition, the peak width after isothermal treatment at $1000^{\circ} \mathrm{C}$ is lower to that observed at $600^{\circ} \mathrm{C}$ or $1000^{\circ} \mathrm{C}$. This fact can be related to a higher homogeneity of the $\mathrm{W}$ local geometry after the isothermal treatment at $1000^{\circ} \mathrm{C}$.

It has been proposed that the spectra of compounds presenting $\mathrm{WO}_{6}$ octahedra are characterized by the presence of a pronounced and broad (width ca. $8.5 \mathrm{eV}$ ) absorption maximum. However, the spectra of compounds presenting tetrahedral $\mathrm{W}$ species present a narrower maximum (width ca. $5.5 \mathrm{eV}$ ) together with an additional small peak at about $15 \mathrm{eV}$ on the higher energy side of the absorption edge. ${ }^{47}$ According to this information; the obtained results lead us to assume that octahedral coordinated hexavalent tungsten ions are present in these tungsten bronzes.

\subsection{Discussion}

Our previous investigations on the $\mathrm{W}-\mathrm{V}-\mathrm{O},{ }^{29} \mathrm{~W}-\mathrm{V}-\mathrm{Nb}-\mathrm{O}{ }^{48}$ and $\mathrm{W}-\mathrm{V}-\mathrm{Mo}-\mathrm{O}{ }^{20}$ systems have shown that under optimum preparation conditions a monophasic $\mathrm{Ax}_{\mathrm{x}}-\mathrm{HTB}$ (A = alkali metals or ammonium cation) phase can be synthesized in which tungsten is partially substituted by vanadium, Nb or Mo. The W/V or W/Mo ratios play a crucial role in stabilizing $h$ - $\mathrm{WO}_{3}$, which has been always referred as a metastable phase in the literature. A certain (V, Mo) substitution rate ( $\sim 10 \%$ for $\mathrm{V}$ and $\sim 25 \%$ for Mo) cannot be surpassed to avoid the formation of other crystal phases. Stable HTB bronze and bronzoid phases are also formed by introducing ions of large size in the tunnels. ${ }^{49}$

In the materials under study, $\mathrm{W}$ has been partially substituted by $\mathrm{Nb}$. XRD patterns of the prepared samples indicated low crystallinity at $600{ }^{\circ} \mathrm{C}$ (see Figure $1 \mathrm{~b}$ ) except in the case of the $\mathbf{C - 6 0 0}$ sample where a highly crystalline Cs-HTB phase is formed. Our results show that samples with $\mathrm{Nb} / \mathrm{W} \geq 1$ (see composition of the synthesis gels on Table 1) are constituted by structurally ill-defined crystal-phases and give rise to 
small crystal size (samples A-600, B-600, D-600 and E-600). The stabilizing role of vanadium towards the HTB type phase is only patent if $\mathrm{Nb} / \mathrm{W}<1$ (see for comparison sample C-600 and D-600). The stabilizing role of cesium can be appreciated from the contrast of B-600 and B1-600: in addition to having sufficient $W$, the higher concentration of Cs enables the HTB skeleton to be initially formed and stabilized at $1000{ }^{\circ} \mathrm{C}$. This is also in agreement with the high crystallinity of Cs-HTB type phase observed in B1-600 and C1-600.

As mentioned, the structural evolution occurring in the samples when heating at high temperature is accompanied by important changes in the chemical composition. This is in agreement with the fact that certain elements have stabilizing character for certain structural types, as we have just discussed. The overall analysis of the structural evolution of the studied samples shows the formation of Cs-HTB and/or Cs-M1 as final phases. Our results show that M1 is formed as single phase in the samples where $\mathrm{Nb} /(\mathrm{W}+\mathrm{V})$ is ca. 1 (i.e. B-1000, D-1000) but not for $\mathrm{Nb} /(\mathrm{V}+\mathrm{W})<1$ as in $\mathbf{C - 1 0 0 0}$ and C1-1000 samples, where vanadium replaces niobium and Cs-HTB is formed. This principle can be assumed for the Mo-substituted sample, where Mo replaces W instead of $\mathrm{Nb}$ and thus, the $\mathrm{M} 1$ type phase is obtained at high temperature (sample $\mathbf{E - 1 0 0 0}$ ).

The M1-type structure was observed in the Cs-Nb-W-O system for the first time 21 and further identified in the Mo-V-O, Mo-V-Te(Sb)-O and MoVNb(Ta)TeO systems. ${ }^{11-16}$ In the unit cell, $\mathrm{MO}_{6}$ sharing corner octahedra are disposed in such a way that they form hexagonal and heptagonal tunnels in addition to four $\mathrm{M}_{6} \mathrm{O}_{21}$ pentagonal units. The structural refinement in the MoVNbTeO system by means of neutron diffraction ${ }^{50}$ and by aberration corrected high-resolution electron microscopy, ${ }^{14}$ has shown that niobium occupies the pentagonal units of the structure in spite of the presence of Mo, which can also stabilize that coordination. In addition, in the work by 
Korovchenko et al ${ }^{51}$ authors show the influence of niobium in stabilizing the M1-type phase, by comparing the quantitative transformation of the orthorhombic M1-phase into the pseudo hexagonal phase (the so-called M2) in the Mo-V-Te-Nb-O and Mo-V-Te-O systems, which only takes place in the last one. In the present case, materials contain $\mathrm{Nb}$ and $\mathrm{W}$ that can also stabilize pentagonal pyramids at high temperatures. However, the experiments show that the thermal structural transformation occurs together with an increment of niobium incorporation in the corresponding crystal phase. There is a cationic redistribution as well as structural reorganization as calcination temperature increases and the nanocrystalline agglomerates of the pristine samples act as chemical reservoirs from which the different constituents incorporate into the crystal phase stabilized at each temperature. Typical compositions of both, the Cs-HTB as well as the M1-type phases are shown in Table 1 for sample $\mathbf{B}, \mathbf{D}$ and $\mathbf{E}$, which demonstrate the progressive incorporation of Nb when increasing temperature. Figure S4 (on Supporting Information) illustrates very well this fact: the image corresponds to the high-resolution electron micrograph of a crystallite of the B-600 sample where the pentagonal pyramids begin to nucleate. The composition of this particular crystal (W: 52\%, Nb: 39.5\% and Cs: $8.5 \%$ ) is in contrast with the average composition of the small crystallites of CsHTB forming the sample at $600^{\circ} \mathrm{C}$ (W: $72 \%, \mathrm{Nb}: 19 \%$ and Cs: $\left.9 \%\right)$

Besides, it is important to emphasize the significance of vanadium or molybdenum in the stability of the M1 phase, as long as it is replacing tungsten. Table 1 shows that the stabilization of M1 takes place but the substitution rate does not surpass $10 \%$ of the positions of the structural framework (sample D-1000 and E-1000). However, when replacing niobium, vanadium or molybdenum prevents the formation of M1 and stabilizes the HTB phase, as we have already mentioned (samples $\mathbf{C}$ and $\mathbf{C 1}$ ). 
Cesium plays also a relevant role in the formation of the M1 phase. Previous investigations in our group have shown that the presence of cesium stabilizes the hexagonal form of $\mathrm{WO}_{3}\left(\mathrm{~h}-\mathrm{WO}_{3}\right)$ and the Cs-HTB phase formed does not decompose at $1000^{\circ} \mathrm{C}$ (unpublished results). In the case that a sufficient amount of niobium is in the synthesis gel, the progressive incorporation precludes the thermal stabilization of HTB and favors the genesis of M1 although cesium is located in the hexagonal and heptagonal tunnels. At this point, it is important to recall that the need of species allocated in the hexagonal and/or heptagonal tunnels in order to stabilize the M1 phase is a well-established fact. ${ }^{11-16}$

The schematic representation of Figure 9a includes all these features. From a topological point of view, transformation from HTB to M1 converts a group of eight hexagonal rings, which consists in 35 metal-oxygen polyhedra, into a total of 37 metaloxygen polyhedra, constituting four pentagonal $\mathrm{M}_{6} \mathrm{O}_{21}$ units, two hexagonal and two heptagonal rings (as illustrated in Figure 9a). A minimal reorganization of the structural elements initially formed is required, as shown. The initially crystallized Cs-HTB phase remains stable upon calcination at $1000^{\circ} \mathrm{C}$ when there is excess cesium, regardless of whether the $\mathrm{Nb} /(\mathrm{W}+\mathrm{Z})$ ratio is 1 (sample $\mathbf{B 1 - 1 0 0 0}$ ) or lower than $1(\mathrm{Z}=\mathrm{V})$ (sample $\mathbf{C 1 -}$ 1000) (Fig. S2, Supporting Information). However, in the absence of excess cesium the $\mathrm{Nb} /(\mathrm{W}+\mathrm{Z})=1$ ratio (samples A-1000, B-1000, D-1000 and E-1000) ensures enough niobium to facilitate the formation of the $\mathrm{M}_{6} \mathrm{O}_{21}$ units, which constitute the new structural element of the M1-type phase. This is in agreement with the progressive incorporation of niobium observed while increasing temperature. In this transformation, the stability of the new heptagonal rings is ensured by the presence of cesium. It has been reported that both hexagonal and heptagonal tunnels are partially occupied by cesium ${ }^{22}$ although direct observation of the tunnels occupancy has not been possible by 
conventional high-resolution transmission electron microscopy. ${ }^{21}$ Figure 9b corresponds to the unprocessed STEM-HAADF image of a crystal of chemical composition Cs0.45( $\left.\mathrm{Nb}_{2.36} \mathrm{~W}_{2.64}\right) \mathrm{O}_{14}$ oriented in the [001] zone axis. Under HAADF imaging conditions, the contrast of the obtained images is roughly proportional to the square of the atomic number $\mathrm{Z}$ of the species so, when adequately projected, it is possible to directly assign the contrast to real chemical contrast. From this statement, it can easily be observed a faint bright contrast inside the hexagonal as well as the heptagonal channels. A partial occupancy of Cs in the channels is consistent with the data from the crystal chemical composition, from which less than half of the available positions are occupied. Similar contrast has been observed in crystals with Cs composition in the range $0.38 \leq \mathrm{x} \leq 0.75$, which is in agreement with the fact that stabilizing species are needed in the structural tunnels (offering robustness to the M1-type structural framework).

\section{Figure 9}

The proposed mechanism of transformation is compatible with the recent observations of He et al. ${ }^{52}$ in Mo-V-Te-Nb(Ta)-O systems. They provide experimental evidence about the M1/M2 epitaxial intergrowth in Mo-V-Te-Ta, showing that the $\mathrm{M}_{6} \mathrm{O}_{21}$ units are compositionally distinct from the hexagonal phase and imply tantalum enrichment in the bipyramidal sites (it is important to recall that Ta shows strong preference for pentagonal bipyramidal coordination as well as $\mathrm{Nb}$ ). Their results suggest that the observed epitaxial growth of $\mathrm{M}_{6} \mathrm{O}_{21}$ type units is strongly associated with the presence of Ta in the system. The $\mathrm{M}_{6} \mathrm{O}_{21}$ units in the Mo-V-Te-Nb system, instead, nucleate apart forming separate particles. Our results did not provide any evidence about the intergrowth of the hexagonal and the orthorhombic phases. It seems, rather, 
that the new structure phase forms from crystallites of the former hexagonal phase together with an additional amount of niobium as raw materials. The big agglomerates constituting the as prepared samples are chemical reservoirs from which crystallites grow. At temperatures up to $600^{\circ} \mathrm{C}$, the Cs-HTB crystal phase is energetically more favorable and the incorporation of niobium is limited. As temperature increases, further niobium diffusion together with a topological reorganization occurs that favors the formation of the $\mathrm{M}_{6} \mathrm{O}_{21}$ units, which serves to nucleate the orthorhombic phase.

The fact that the results presented in this work for the Cs-Nb-W-O mixed oxides with low catalytic activity are compatible with the most recent observations at the mesoscale in the isostructural $\mathrm{Mo}-\mathrm{V}-\mathrm{Te}-\mathrm{Nb}(\mathrm{Ta})-\mathrm{O}$ mixed oxides that are very active catalysts, allows assuming that the described nucleation/structural transformation process can be extended to any functional system structurally related. This behavior makes an important contribution to the understanding of the scenario in which M1 grows and can be a new approach to optimize its catalytic performance through a better control of the participating species and their crystal chemical effect.

\section{Associated Content}

\section{Supporting Information}

The following information is available free of charge on the ACS Publications website at doi:__ : Powder X-ray diffraction patterns of B-series samples; Powder Xray diffraction patterns of samples prepared with excess of Cs in the synthesis gel; FTIR spectra of samples B-1000, D-1000 and E-1000; High-resolution electron micrograph of a crystallite of B-600.

\section{Author Information}


Corresponding Author

E-mail for C.C.L.: jmlopez@itq.upv.es; esterg@quim.ucm.es Notes

The authors declare no competing financial interests.

\section{Acknowledgements}

MDS and JMLN thank the Spanish Government-MINECO projects (CTQ2015-68951C3-1-R and SEV-2012-0267). EGG acknowledges the financial support through projects MAT2013-46452-C4 and MAT2016-78362-C4-4-R and the valuable help of Dr. Urones-Garrote in STEM performing. Authors thank the ICTS Centro Nacional de Microscopia Electrónica (UCM) for instrumental facilities and LNLS/CNPEM-Brazil for the synchrotron radiation facilities.

\section{References}

1. a) Dickens, P.G.; Whittingham, M.S. The Tungsten Bronzes and Related Compounds. Q. Rev. Chem. Soc. 1968, 22, 30-44; b) Chernova, N.A.; Roppolo, M.; Dillon, A.C.; Whittingham, M.S. Layered Vanadium and Molybdenum Oxides: Batteries and Electrochromics. J. Mater. Chem. 2009, 19, 2526-2552.

2. Greenblatt, M. Molybdenum Oxide Bronzes with Quasi-Low-Dimensional Properties. Chem. Rev. 1988, 88, 31-53.

3. Labbe, Ph. Tungsten Oxides, Tungsten Bronzes and Tungsten Bronze-type structures. Key Eng. Mater. 1992, 68, 293-339.

4. Bartha, L.; Kiss, A. B.; Szalay, T. Chemistry of Tungsten Oxide Bronzes. Int. J. Refract. Met. Hard Mater. 1995, 13, 77-91.

5. Michailovski, A.; Kiebach, R.; Bensch, W.; Grunwaldt, J.D.; Baiker, A.; Komarneni, S.; Patzke, G.R. Morphological and Kinetic Studies on Hexagonal Tungstates. Chem. Mater. 2007, 19, 185-197. 
6. Chernova, N.A.; Roppolo, M.; Dillon, A.C.; Whittingham, M.S. Layered Vanadium and Molybdenum oxides: Batteries and Electrochromics. J. Mater. Chem. 2009, 19, 2526-2552.

7. Zhou, L.; Zhu, J.; Yu, M.; Huang, X.; Li, Z.; Wang, Y.; Yu, Ch. $\mathrm{Mo}_{x} \mathrm{~W}_{1-x} \mathrm{O}_{3} \cdot 0.33 \mathrm{H}_{2} \mathrm{O}$ Solid Solutions with Tunable Band Gaps. J. Phys. Chem. C 2010, 114, 20947-20954.

8. Saji, W.S.; Lee, Ch.-W. Molybdenum, Molybdenum Oxides, and their Electrochemistry. ChemSusChem 2012, 5, 1146 - 1161.

9. Rödel, E.; Timpe, O.; Trunschke, A.; Zenkovets, G.A.; Kryukova, G.N.; Schlögl, R.; Ressler, T. Structure Stabilizing Effect of Tungsten in Mixed Molybdenum Oxides with $\mathrm{Mo5O}_{14}$-type Structure. Catal. Today 2007, 126, 112-118.

10. Tsuji, H.; Koyasu, Y. Synthesis of MoVNbTe(Sb)Ox Composite Oxide Catalysts via Reduction of Polyoxometalates in an Aqueous Medium. J. Am. Chem. Soc. 2002, 124, 5608-5609.

11. a) Millet, J.M.M.; Roussel, H.; Pigamo, A.; Dubois, J.L.; Jumas, J.C. Characterization of Tellurium in MoVTeNbO Catalysts for Propane Oxidation or Ammoxidation. Appl. Catal. A: Gen. 2002, 232, 77-92; b) Woo, J.; Sanghavi, U.; Vonderheide, A.; Guliants, V.V. A study of M1/M2 Phase Synergy in the MoVTe(Nb,Ta)O Catalyst for Propane Ammoxidation to Acrylonitrile, Appl. Catal. A: Gen. 2016, 515, 179-189.

12. a) Botella, P.; García-González, E.; López Nieto, J.M.; González-Calbet, J. MoVTeNbO Multifunctional Catalysts: Correlation Between Constituent Crystalline Phases and Catalytic Performance. Solid State Sci. 2005, 7, 507-519; b) Concepción, P.; Hernandez, S.; Lopez Nieto, J.M. On the Nature of Active Sites in MoVTeO and MoVTeNbO Catalysts: The Influence of Catalyst Activation Temperature. Appl. Catal. A: Gen. 2011, 391, 92-101.

13. Sanchez Sanchez, M.C.; Girgsdies, F.; Jastak, M.; Kube, P.; Schlögl, R.; Trunschke, A. Aiding the Self-Assembly of Supramolecular Polyoxometalates under Hydrothermal Conditions To Give Precursors of Complex Functional Oxides. Angew. Chem. Int. Ed. 2012, 51, 7194-7197.

14. Sadakane, M.; Yamagata, K.; Kodato, K.; Endo, K.; Toriumi, K.; Ozawa, Y.; Ozeki, T.; Nagai, T.; Matsui, Y.; Sakaguchi, N.; Pyrz, W.D.; Buttrey, D.J.; Blom, D.A.; Vogt, T.; Ueda, W. Synthesis of Orthorhombic Mo-V-Sb Oxide Species by 
Assembly of Pentagonal $\mathrm{Mo}_{6} \mathrm{O}_{21}$ Polyoxometalate Building Blocks. Angew. Chem. Int. Ed. 2009, 121, 3840-3844.

15. Hibst, H.; Rosowski, F.; Cox, G. New Cs-containing Mo- $\mathrm{V}^{4+}$ Based Oxides with the Structure of the M1 Phase-Base for New Catalysts for the Direct Alkane Activation. Catal. Today 2006, 117, 234-241.

16. López Nieto, J.M.; Botella, P.; Vázquez, M.I.; Dejoz, A. The Selective Oxidative Dehydrogenation of Ethane over Hydrothermally Synthesized MoVTeNb Catalysts Chem. Commun. 2002, 1906-1907.

17. a) Zheng, J.Y.; Aider, Z.H.; Van, T. K.; Pawar, A.U.; Kang, M.J.; Kim, Ch.W.; Kang, Y. S. Tuning of the Crystal Engineering and Photoelectrochemical Properties of Crystalline Tungsten Oxide for Optoelectronic Device Applications. CrystEngComm. 2015, 17, 6070-6093; b) Heinrich, Ch.P.; Schrade, M.; Cerretti, G.; Lieberwiith, I.; Leidich, P.; Schmitz, A.; Fjeld, H.; Mueller, E.; Finstad, T.G.; Norby, T.; Tremel, W. Tetragonal Tungsten Bronzes $\mathrm{Nb}_{8-x} \mathrm{~W}_{9+x} \mathrm{O}_{47-\delta}$ : Optimization Strategies and Transport Properties of a New n-Type Thermoelectric Oxide. Mater. Horizons 2015, 2, 519-527.

18. Griffith, G.S.; Luca, V.; Hanna, J.V.; Pike K.J.; Smith, M.E.; Thorogood, G.S. Microcrystalline Hexagonal Tungsten Bronze. 1. Basis of Ion Exchange Selectivity for Cesium and Strontium. Inorg. Chem. 2009, 48, 5648-5662.

19. Liu, B.; Mu, W.; Xie, X.; Li, X.; Wei, H.; Tan, Zh.; Jiamn, Y.; Luo, Sh. Enhancing the Adsorption Capacity of $\mathrm{Sr}^{2+}$ and $\mathrm{Cs}^{+}$onto Hexagonal Tungsten Oxide by Doped Niobium. RSC Adv. 2015, 5, 15603-15611.

20. Chieregato, A.; Soriano, M.D.; García-González, E.; Puglia, G.; Basile, F.; Concepción, P.; Bandinelli, C.; López Nieto, J.M.; Cavani, F. Multielement Crystalline and Pseudocrystalline Oxides as Efficient Catalysts for the Direct Transformation of Glycerol into Acrylic Acid. ChemSusChem 2015, 8, 398-406.

21. Lundberg, M.; Sundberg, M. New Complex Structures in the Cesium-NiobiumTungsten-Oxide System Revealed by HREM. Ultramicroscopy 1993, 52, 429-435.

22. Weirich, T.E.; Portillo, J.; Cox, G.; Hibst, H.; Nicolopoulos, S. Ab Initio Determination of the Framework Structure of the Heavy-Metal Oxide $\mathrm{Cs}_{\mathrm{x}} \mathrm{Nb}_{2.54} \mathrm{~W}_{2.46} \mathrm{O}_{14}$ from $100 \mathrm{kV}$ Precession Electron Diffraction Data. Ultramicroscopy 2006, 106, 164-175.

23. Sharma, R. Bronzoid phases in the pseudo-binary system $A_{x} \mathrm{Nb}_{x} \mathrm{~W}_{1-x} \mathrm{O}_{3}$ with $A=\mathrm{K}$ and Cs. Mat. Res. Bull 1985, 20, 1373-1381. 
24. Dey, K.; R. Debnath, T.; Rüscher, C. H.; Sundberg, M.; Hussain, A. Synthesis and Characterization of Niobium Doped Hexagonal Tungsten Bronze in the Systems, $\mathrm{Cs}_{\mathrm{x}} \mathrm{Nb}_{\mathrm{y}} \mathrm{W}_{1-\mathrm{y}} \mathrm{O}_{3}$. J. Mater. Sci. 2011, 46, 1388-1395.

25. Abdullah, A.M.; Debnath, T.; Rsücher, C.H.; Hussain, A. Synthesis and Characterization of Vanadium Substituted Potassium Tungsten Bronzes, $\mathrm{K}_{\mathrm{x}} \mathrm{V}_{\mathrm{y}} \mathrm{W}_{1 \text { - }}$ yО3. J. Sci. Res. 2012, 4, 507-514.

26. Li, L., Jiang, F., Tu, F., Jia, S., Gao, Y., Wang, J. Atomic-Scale Study of Cation Ordering in Potassium Tungsten Bronze Nanosheets, Adv. Sci. 2017, 4, 1600537.

27. Li, G.; Guo, Ch.; Yan, M.; Liu, S. $\mathrm{Cs}_{\mathrm{x}} \mathrm{WO}_{3}$ Nanorods: Realization of Full Spectrum Responsive Photocatalytic Activities from UV, Visible to Near-Infrared Region, Appl. Catal. B: Environ. 2016, 183, 142-148.

28. Debnath, T.; Roy, S. Ch.; Rüscher, C. H.; Hussain, A. Synthesis and Characterization of Niobium-Doped Potassium Tetragonal Tungsten Bronzes, $\mathrm{K}_{\mathrm{x}} \mathrm{Nb}_{\mathrm{y}} \mathrm{W}_{1-\mathrm{y}} \mathrm{O}_{3}$. J. Mater. Sci. 2009, 44, 179-185.

29. García-González, E.; Soriano, M.D.; Urones-Garrote, E.; López Nieto, J.M. On the Origin of the Spontaneous Formation of Nanocavities in Hexagonal Bronzes (W,V)Оз. Dalton Trans. 2014, 43, 14644-14652.

30. a) Okumura, K.; Tomiyama, T.; Shirakawa, S.; Ishida, S.; Sanada, T.; Arao, M.; Niwa, M. Hydrothermal Synthesis and Catalysis of $\mathrm{Nb}_{2} \mathrm{O}_{5}-\mathrm{WO}_{x}$ Nanofiber Crystal. $J$. Mater. Chem. 2011, 21, 229-235; b) Yu, J.; Yuan, L.; Wen, H.; Shafiei, M.; Field, M. R.; Liang, J.; Yang, J.; Liu, Z.F.; Wlodarski, W.; Motta, N.; Li, Y.X.; Zhang, G.; Kalantar-Zadeh, K.; Lai, P.T. Hydrothermally Formed Functional Niobium Oxide Doped Tungsten Nanorods. Nanotechnology 2013, 24, 495501.

31. Blom, D.A.; Li, X.; Mitra, S.; Vogt, Th.; Buttrey, D.J. STEM HAADF Image Simulation of the Orthorhombic M1 Phase in the Mo-V-Nb-Te-O Propane Oxidation Catalyst. ChemCatChem 2011, 3, 1028- 1033.

32. a) Chen, Ch.; Kosuke, N.; Murayama, T.; Ueda, W. Single-Crystalline-Phase MoзVOx: An Efficient Catalyst for the Partial Oxidation of Acrolein to Acrylic Acid. ChemCatChem 2013, 5, 2869 - 2873; b) Konya, T.; Katou, T.; Murayama, T.; Ishikawa, S.; Sadakane, M.; Buttrey, D.; Ueda, W. An Orthorhombic Moз $\mathrm{VO}_{x}$ Catalyst Most Active for Oxidative Dehydrogenation of Ethane Among Related Complex Metal Oxides. Catal. Sci. Technol. 2013, 3, 380-387.

33. Simon, A.; Kondratenko, E.V.; The «Flash» Method: A Shortcut for Producing $\mathrm{Cs}_{\mathrm{x}}(\mathrm{W}, \mathrm{Nb})_{5} \mathrm{O}_{14}$ Structure. Chem. Eur. J. 2010, 16, 1765-1767. 
34. Barthel, J.; Weirich, Th. E.; Cox, G.; Hibst, H.; Thust, A. Structure of Cs0.5[Nb2.5W2.5O14] Analyzed by Focal-Series Reconstruction and Crystallographic Image Processing. Acta Materialia 2010, 58, 3764-3772.

35. Liu, J.-X.; Ando, Y.; Dong, X.-L.; Shi, F.; Yin, S.; Adachi, K.; Chonan, T.; Tanaka, A.; Sato T. Microstructure and Electrical-Optical Properties of Cesium Tungsten Oxides Synthesized by Solvothermal Reaction Followed by Ammonia Annealing. $J$. Solid State Chem. 2010, 183, 2456-2460.

36. a) Shi, F.; Liu, J.; Dong, X.; Xu, Q.; Luo, J.; Ma, H. Hydrothermal Synthesis of $\mathrm{Cs}_{\mathrm{x}} \mathrm{WO}_{3}$ and the Effects of $\mathrm{N}_{2}$ Annealling on its Microstructure and Heat Shielding Properties. J. Mater. Sci. Technol. 2014, 30, 342-346.; b) Guo, Ch.; Yi, Sh.; Yan, M.; Sato, T. Facile Synthesis of Homogeneous Cs $x$ WO 3 Nanorods with Excellent LowEmissivity and NIR Shielding Property by a Water controlled-Release Process. $J$. Mater. Chem. 2011, 21, 5099-5105.

37. Omata, K.; Izumi, S.; Murayama, T.; Ueda, W. Hydrothermal Synthesis of W-Nb Complex Metal Oxides and Their Application to Catalytic Dehydration of Glycerol to Acrolein. Catal. Today 2013, 201, 7- 11.

38. Macalik, L.; Maczka, M.; Hanuza, J.; Bednarkiewicz, A.; Hreniak, D.; Strek, W.; Majchrowski, A. Structure and Properties of the $\mathrm{KNbW}_{2} \mathrm{O}_{9}$ Hexagonal Bronze Doped with $\mathrm{Eu}^{3+}$ Ions as an Optically Active Probe. J. Alloys Comp. 2004, 380, 248-254.

39. Guo, Ch.; Yin, Sh.; Dong, Q.; Sato, T. Simple Route to $\left(\mathrm{NH}_{4}\right)_{\mathrm{x}} \mathrm{WO}_{3}$ Nanorods for Near Infrared Absorption. Nanoscale 2012, 4, 3394-3398.

40. Huo, L.; Zhao, H.; Mauvy, F.; Fourcade, S.; Labrugere, Ch.; Pouchard, M.; Grenier, J.-C. Synthesis and Mixed Conductivity of Ammonium Tungsten Bronze with Tunneling Structures. Solid State Sci. 2004, 6, 679-688.

41. Gotica, M.; Ivanda, M.; Popovic, S.; Music, S. Synthesis of Tungsten Trioxide Hydrates and Their Structural Properties. Mater. Sci. Eng. B 2000, 77, 193-201.

42. Maczka, M.; Hanuza, J.; Kojima, S.; Majchrowski, A.; van der Maas, J.H. Vibrational Spectra of $\mathrm{KNbW}_{2} \mathrm{O}_{9}$ Hexagonal Tungsten Bronze. J. Raman Spectrosc. 2001, 32, 287-2291.

43. Botella, P.; Solsona, B.; López Nieto, J. M.; Concepción, P.; Jordá, J.L.; Doménech-Carbó, M.T. Mo-W-Containing Tetragonal Tungsten Bronzes Through Isomorphic Substitution of Molybdenum by Tungsten. Catal. Today 2010, 158, 162-169. 
44. Jehng, J. M.; Wachs, I. E. Niobium Oxide solution Chemistry. J. Raman Spectrosc. 1991, 22, 83-89.

45. Antonio, M.R.; Song, I.; Yamada, H. Coordination and Valence of Niobium in $\mathrm{TiO}_{2}-\mathrm{NbO}_{2}$ Solid Solutions Through X-Ray Absorption Spectroscopy. J. Solid State Chem. 1991, 93, 183-192.

46. Schimanke, G.; Martin, M.; Kunert, J.; Vogel, H. Characterization of Mo-V-W Mixed Oxide Catalysts by ex situ and in situ X-Ray Absorption Spectroscopy. Z. Anorg. Allg. Chem. 2005, 631, 1289-1296.

47. Yamazoe, S.; Hitomi, Y.; Shishido, T.; Tanaka, T. XAFS Study of Tungsten L1and L3-Edges: Structural Analysis of $\mathrm{WO}_{3}$ Species Loaded on $\mathrm{TiO}_{2}$ as a Catalyst for Photo-oxidation of NH3. J. Phys. Chem. C 2008, 112, 6869-6879.

48. Chieregato, A.; Soriano, M.D.; Basile, F.; Liosi, G.; Zamora, S.; Concepcion, P.; Cavani, F.; Lopez Nieto, J.M. One-pot Glycerol Oxidehydration to Acrylic Acid on Multifunctional Catalysts: Focus on the Influence of the Reaction Parameters in Respect to the Catalytic Performance. Appl. Catal. B: Environ. 2014, 150-151, 3746.

49. Guo, J.-D.; Whittingham, M.S. Tungsten Oxides and Bronzes: synthesis, Diffusion and Reactivity. Int. J. Mod. Phys. B 1993, 7, 4145-4164.

50. Murayama, H.; Vitry, D.; Ueda, W.; Fuchs, G.; Anne, M.; Dubois, J.L. Structure Characterization of Orthorhombic Phase in MoVTeNbO Catalyst by Powder X-ray Diffraction and XANES. Appl. Catal. A: Gen. 2007, 318, 137-142.

51. Korovchenko, P.; Shiju, N. R.; Dozier, A. K.; Graham, U. M.; Guerrero-Pérez, M. O.; Guliants, V. V. M1 to M2 Phase Transformation and Phase Cooperation in Bulk Mixed Metal Mo-V-M-O (M=Te, Nb) Catalysts for Selective Ammoxidation of Propane. Top. Catal. 2008, 50, 43-51.

52. He, Q. Woo, J. Belianinov, A. Guliants, V. V. Borisevich,A. Y. Better Catalysts through Microscopy: Mesoscale M1/M2 Intergrowth in Molybdenum-Vanadium Based Complex Oxide Catalysts for Propane Ammoxidation. ACSNano 2015, 9 3470-3478. 
Table 1. Characteristics of as-synthesized and calcined samples.

\begin{tabular}{|c|c|c|c|}
\hline Sample ${ }^{(a)}$ & $\begin{array}{l}\text { Metal ratio in the } \\
\text { synthesis gel } \\
(\mathrm{Cs} / \mathrm{Nb} / \mathrm{W} / \mathrm{Z})^{(\mathrm{b})}\end{array}$ & Powder XRD & $\begin{array}{l}\text { Average Metal ratio in } \\
\text { the crystals }{ }^{(c)}\end{array}$ \\
\hline & $0.5 / 2.5 / 2.5 / 0$ & & \\
\hline A-pr & & pseudocrystalline & \\
\hline A-600 & & pseudocrystalline & \\
\hline \multirow[t]{3}{*}{ A-1000 } & & $\mathrm{HTB}+\mathrm{M} 1$ & $\mathrm{Cs}_{0.30} \mathrm{~W}_{0.72} \mathrm{Nb}_{0.28}(\mathrm{HTB})$ \\
\hline & & & $\mathrm{Cs}_{0.60} \mathrm{Nb}_{2.40} \mathrm{~W}_{2.60}(\mathrm{M} 1)$ \\
\hline & $0.5 / 2.5 / 2.5 / 0$ & & \\
\hline B-pr & & HTB & \\
\hline B-600 & & HTB $^{d}$ & $\mathrm{Cs}_{0.10} \mathrm{~W}_{0.79 \mathrm{Nb}_{0.21}}$ \\
\hline \multirow[t]{2}{*}{ B-1000 } & & M1 & 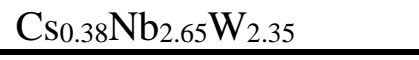 \\
\hline & $1.5 / 2.5 / 2.5 / 0$ & & \\
\hline B1-pr & & НTB & \\
\hline B1-600 & & НТВ & \\
\hline \multirow[t]{2}{*}{ B1-1000 } & & HTB & \\
\hline & $0.5 / 1.5 / 2.5 / 1(\mathrm{Z}=\mathrm{V})$ & & \\
\hline C-pr & & НТВ & \\
\hline C-600 & & НТВ & $\mathrm{Cs}_{0.33} \mathrm{~W}_{0.68} \mathrm{Nb}_{0.25} \mathrm{~V}_{0.07}$ \\
\hline \multirow[t]{2}{*}{ C-1000 } & & HTB & $\mathrm{Cs}_{0.33} \mathrm{~W}_{0.68} \mathrm{Nb}_{0.25} \mathrm{~V}_{0.07}$ \\
\hline & $1.5 / 1.5 / 2.5 / 1(\mathrm{Z}=\mathrm{V})$ & & \\
\hline C1-pr & & НТВ & \\
\hline C1-600 & & НTB & \\
\hline \multirow[t]{2}{*}{ C1-1000 } & & HTB & \\
\hline & $0.5 / 2.5 / 1.5 / 1(\mathrm{Z}=\mathrm{V})$ & & \\
\hline D-pr & & pseudocrystalline & \\
\hline D-600 & & pseudocristalline & $\mathrm{Cs}_{0.22} \mathrm{~W}_{0.67} \mathrm{Nb}_{0.26} \mathrm{~V}_{0.07}$ \\
\hline \multirow[t]{2}{*}{ D-1000 } & & M1 & 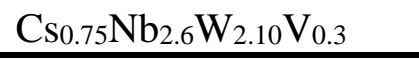 \\
\hline & 0.5/2.5/1.25/1.25 (Z=Mo) & & \\
\hline E-pr & & pseudocrystalline & \\
\hline E-600 & & pseudocrystalline & 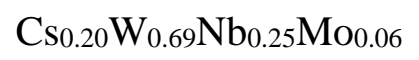 \\
\hline E-1000 & & M1 & $\mathrm{Cs}_{0.75} \mathrm{Nb}_{2.55} \mathrm{~W}_{2.0 \mathrm{Mo}_{0.4}}$ \\
\hline
\end{tabular}

(a) Sample: pristine (pr) or heat-treated at 600 or $1000^{\circ} \mathrm{C}$.

(b) $\mathrm{Cs} / \mathrm{Nb} / \mathrm{W} / \mathrm{Z}(\mathrm{Z}=\mathrm{Mo}, \mathrm{V})$ metal ratio in the synthesis gel.

(c) Crystal by crystal EDXS microanalysis. Cationic ratios expressed on the basis of the $\mathrm{Cs}_{0.33} \mathrm{~W}_{1-\mathrm{x}}(\mathrm{Nb}, \mathrm{V})_{\mathrm{x}} \mathrm{O}_{3}$ and $\mathrm{Cs}_{0.5} \mathrm{Nb}_{2.5} \mathrm{~W}_{2.5} \mathrm{O}_{14}$ stoichiometry, for the Cs-HTB and the Cs-M1 phase, respectively.

(d) Low crystallinity. 


\section{Caption to Figures}

Fig. 1. Powder X-ray diffraction patterns of Cs-W-Nb (A- and B-series), Cs-W-Nb-V (C- and D -series) and Cs-W-Nb-Mo (E-series) samples: a) pristine; b) heattreated at $600^{\circ} \mathrm{C}$; c) heat-treated at $1000^{\circ} \mathrm{C}$. Reference patterns corresponding to $\mathrm{Cs}_{0.2} \mathrm{~W}_{0.8} \mathrm{Nb}_{0.2} \mathrm{O}_{3}$ (ICDD 00-39-0812) and $\mathrm{Cs}_{2.52}\left[\mathrm{~W}_{2.46} \mathrm{Nb}_{2.54} \mathrm{O}_{14}\right]$ (ICDD 01-0765882) have been included as a help for the reader.

Fig.2. In-situ synchrotron XRD patterns obtained on air stream for sample A (a) in the temperature range from ambient to $975^{\circ} \mathrm{C}$ and (b) under isothermal conditions at $975^{\circ} \mathrm{C}$ and variable time. Broad peak at $2 \theta \approx 6^{\circ}$ (marked *) is caused by the kapton window of the furnace.

Fig.3. (a) Electron diffraction ring pattern obtained from the A-600 sample. Miller index of the ring set has been indexed according to the Cs-HTB crystal phase. (b) Low magnification electron micrograph of a group of crystals of the A-600 sample. (c) High resolution image of one of those crystallites of Cs-HTB oriented in the [100] zone axis. The corresponding Fast Fourier Transform (FFT) is shown as inset.

Fig.4. High resolution images of two different crystals of the sample B-1000 oriented in the [102] (a) and [100] (b) zone axes of the $\mathrm{Cs}_{\mathrm{x}}(\mathrm{Nb}, \mathrm{W})_{5} \mathrm{O}_{14}$ crystal phase. Insets show the corresponding Fast Fourier Transforms (FFT).

Fig. 5. ATG and DSC curves corresponding to samples B-pr and B-600.

Fig. 6. FTIR and Raman spectra corresponding to B-series samples: B-pr (a, d), B-600 (b, e) and B-1000 (c, f). 
Fig. 7. Normalized Nb K-edge XANES spectra of : a) Cs-W-Nb-O solids heat-treated at $600,(\mathbf{B}-600)$ and $1000^{\circ} \mathrm{C}(\mathbf{B}-1000)$ and $\mathrm{Nb}_{2} \mathrm{O}_{5}$ reference; $\left.\mathrm{B}\right)$ in situ study on the evolution with heat-treatment temperature of B-pr sample from 50 to 1000, followed to isothermal treatment at $1000^{\circ} \mathrm{C}$ (time from 0 to $50 \mathrm{~min}$ )

Fig. 8. Normalized W L3-edge XANES spectra of Cs-W-Nb-O solids: in-situ study on the evolution with heat-treatment temperature of B-pr sample from 50 to 1000, followed to isothermal treatment at $1000^{\circ} \mathrm{C}$ (time from 0 to $50 \mathrm{~min}$ ).

Figure 9. (a) Schematic representation showing the topological relationship between the two crystal phases. A portion of Cs-HTB phase consisting on 35 polyhedra is transformed into the 37 polyhedra that constitute the structural element in the M1type phase (see text) whenever diffusion of extra niobium takes place, which enables the formation of the $\mathrm{M}_{6} \mathrm{O}_{21}$ units. From bottom to top, there is an increasing amount of caesium resembled by the partial occupation of the hexagonal tunnels in the HTB phase. (b) Unprocessed STEM-HAADF image of a crystal of chemical composition $\mathrm{Cs}_{0.45}\left(\mathrm{Nb}_{2.36} \mathrm{~W}_{2.64}\right) \mathrm{O}_{14}$ oriented in the [001] zone axis, showing the occupation of both the hexagonal and the heptagonal tunnels. The structural element defined on part (a) is overlapped as a help for the reader. Representation of a portion of a crystal of the $\mathrm{Cs}_{\mathrm{x}}(\mathrm{Nb}, \mathrm{W})_{5} \mathrm{O}_{14}$ structure phase in the [001] projection. Highlighted is the structural element of 37 polyhedra. 


\section{Synopsis:}

The structural transformation process of the hexagonal bronze $\mathrm{Cs}_{0.2}(\mathrm{~W}, \mathrm{Nb}) \mathrm{O}_{3}$ to the orthorhombic Cs0.5(Nb2.5W2.5)O14 crystal phase has been explained. Our understanding on this transformation process can be extended to any structurally related functional system and contributes to a comprehensive scenario for the crystal growth of the M1 catalyst phase and its relationship with the M2 phase. 